\title{
FOUNDATIONAL MYTHS: \\ Country and conservation in Australia
}

\author{
Transforming Cultures eJ ournal, \\ Vol. 3 No 1, February 2008 \\ http:// epress.lib.uts.edu.au/journals/TfC
}

\section{Michael Adams ${ }^{1}$}

\section{Introduction}

In Australia, while each state has responsibility for the creation and management of their own national park systems, overall coordination is achieved through the Commonwealth National Reserve System. The Australian systems, like many others, are essentially based on the 'Yellowstone model' of protected areas: government owned and managed, precise boundaries, and with people present only as visitors or rangers (Stevens 1997). The Yellowstone model had its origins in wilderness protection, and despite many changes, wilderness persists as a foundational concept for Australian national parks.

In the last two decades, the presence of Aboriginal people, Aboriginal land, and Aboriginal issues have increasingly interacted with notions of national parks and protected areas generally. Today, the concept of 'joint management' between conservation agencies and Indigenous people is established in a number of jurisdictions, and Aboriginal people continue to push for greater involvement and control in conservation and national park issues. For most Aboriginal people, 'wilderness' is a meaningless concept: Australia has been an occupied landscape for millennia, home to thousands of generations of Aboriginal people (Langton 1998).

\footnotetext{
${ }^{1}$ Michael Adams is a Senior Lecturer in the Woolyungah Indigenous Centre at the University of Woolongong.
} 
Indigenous people are the most socio-economically disadvantaged group in Australian society (SCRGSP 2007). As a consequence, Aboriginal people are looking for land, a place in the economy, and room for cultural autonomy. Their interests in national parks stem from all these interests: connection to country, 'real' jobs, caring for country. While the two sides of the relationship look very different, the elements for constructive engagement are present. The challenge is to learn from the history of policy failure and envisage new futures founded on new paradigms.

\section{Culture and Conservation}

Four core characteristics of the relationships between Aboriginal people and state conservation agencies are evident. First, looking at the broadest level, the National Reserve System program is essentially about a government reserve system. While there is provision for non-Crown tenures, it needs the imprimateur of the government. The National Reserve System is about more reserves, including on existing Aboriginal land. Parallel to this is the growth in NGO and private 'reserve systems' (for example, the Australian Bush Heritage Fund, Birds Australia, Australian Wildlife Conservancy). Again, this means more land coming into protected areas. For both government and non-government, these increases in land area are seldom matched by increases in management capacity, so visitation is often discouraged. In off-reserve conservation activities, the general emphasis in policy is regulation: for example, threatened species legislation and vegetation clearing controls, with an 'add-on' of conservation agreements and other incentive mechanisms.

The second characteristic is that, structurally, while comparatively decentralised organisations, state conservation agencies nevertheless centralise power and control. Conservation is a global, abstract agenda: particular plants and animals are abstracted to 'biodiversity', particular places to 'the reserve system'. The agencies are professionalised, management-focused bureaucracies with high levels of staff mobility.

Third, a young and growing Aboriginal population is increasingly asserting rights to land and its elements. Land in existing and proposed national parks is important to Aboriginal people, as well as other areas. Species regarded as 'significant' by 
conservation agencies are important to Aboriginal people for entirely different reasons and may be put to entirely different uses.

Finally, land rights in all states except the Northern Territory have delivered little land to Aboriginal people. Much of this has been strongly contested by the state conservation agencies or is coveted by them. Native title challenges the notion of sequestered tenures, but this has not yet been effectively explored in relation to national parks, except, again in the Northern Territory and limited examples in New South Wales. Various models of joint management are operating in Australia, and these will be discussed more below.

State conservation agencies, as subsets of the dominant Australian culture, hold normative cultural constructs which may often be only tenuously linked to the 'realities' they symbolise. These constructs are institutionalised in the structure and processes of conservation agencies, and, as such, have a constant presence in the policy and decisionmaking process. Significant cultural constructions include those focusing on 'nature' and 'Aboriginality' and a spectrum of detailed issues around these. Contemporary Aboriginal interests in conservation issues have to engage and negotiate with this culture of conservation. Aboriginal constructions of nature and indigeneity may differ strongly from those held by conservation agencies.

A fundamental defining theme is that these relationships are cross-cultural: the cultures, while internally heterogeneous, are strongly differentiated from each other. While this expresses itself in a number of ways, my focus is on some of the differences in worldviews and how this articulates to on-ground activities: constructions of nature and race and their outcomes. These relationships also tend to be adversarial and conflictual. The dominant, non-Aboriginal, conservation agency ideology and epistemology assumes superiority (not just to Aboriginal ideologies, but to all comers: four wheel drive enthusiasts, environment NGOs, cultures where coastal foraging and harvesting is the norm). Aboriginal cultural approaches then have to actively assert their beliefs and values against this assumed superiority, and conservation agencies oppose their validity (that land is home, that plants and animals are to be eaten and otherwise used).

The conservation movement (in its broadest sense, including government agencies) legitimates itself through reductionist scientific approaches, overlying a nineteenth century European Romantic ideology. Most of the conservation movement rejects 
attempts to deconstruct this foundation and pays little attention to critiques from the social sciences focusing on the implications of social constructionism. Ironically, the prioritisation of 'natural places' by conservation biology is itself based on a particular construction of nature defined by clearly cultural values.

Today, in biodiversity conservation, mainstream Australia depends on Aboriginal land to achieve the National Reserve System, sometimes on Aboriginal knowledge to effectively survey for biodiversity, on Aboriginal culture to promote tourism in national parks and elsewhere. From the international tourist demand for Aboriginal 'experiences' to the pervasive use of Aboriginal symbols in Australian products and corporations, Aboriginal skills and knowledge, and in fact Aboriginality, are revealed as indispensable to other Australians.

\section{Foundational Myths}

Much of Western epistemology is based on the Cartesian concept of binaries, including the human/nature division. Strong adherence to particular worldviews and a dualistic thinking leads to the conflictual situations evident between Aboriginal communities and conservation agencies.

Binaries need not, however, be individual and oppositional, they could be relational and generative. The notion of 'complementarity' is based on a relational understanding: different epistemologies have points of connection, from which future working relationships, and on-ground results, can be born. The connections are relational and contingent, and, to work for both parties, need to be reciprocal. This approach contrasts complementarity to conflict. This is a complex process of discovering the relationships between two sets of cultural values negotiating in the same space. The epistemologies, worldviews, myths and values are definitively different, but this otherness is to be treated with respect, not dismissed (Salmond 1997).

Maori academic Paul Tapsell (1999, pers comm 22 June) presents a view of how complementarity works in Maori culture: 
these 'opposites' (such as male/female, sky/earth, science/religion, ...western/aboriginal, guest/host) are seen as exciting points of connection from which new ideas, concepts, ways of looking at the world can be born, not out of conflict (negative) but out of complementarity (positive).

My understanding of complementarity is based on the fundamental point that it requires understanding of the other position, and acceptance of its cultural validity, rather than denial or dismissal. From understanding, real communication and negotiation can develop. Note that this is not, however, automatically unproblematic: both parties need to work actively at it, and be alert to developing problems.

The physical and social Australian landscape is vastly changed in the last two centuries. 'Traditional' Aboriginal land management techniques probably did not evolve in contexts of rapid environmental change and will not necessarily work in them. Similarly, conservation biology based on island biogeography theory is not sufficient for the rate of change and the new understandings of ecosystem resilience and multiple stable states. Aboriginal social structures and institutions are changing, just as are Western social structures and institutions, in response to globalisation and a host of smaller scale environmental, economic, institutional and social influences.

\section{Wilderness and science}

The foundational myth for Western conservation as it developed from the United States has been wilderness, but relatively recently this has been overlain (not dislodged) by conservation science. Both of these myths are based around achieving conservation by removing people from 'nature'. Muir (2005, p4) asserts that 'New South Wales (NSW) has earned a reputation as the centre of wilderness protection in Australia', which is at once ironic (as NSW has the greatest population of all states) and obvious, as wilderness is as much, as Nash (2003) identifies, a state of mind as it is an area of land. Aboriginal academic Marcia Langton (1996, p24) strongly challenges concepts of wilderness: 'just as terra nullius was a lie, so was this European fantasy of wilderness. There is no wilderness, but there are cultural landscapes'. The diversity and contradiction of strongly held positions on wilderness is indicative of its centrality as an icon, which also explains the ease with which the contradictions are absorbed. 
Grove (1992, 1995) identifies Romantic scientists as the pioneers of modern environmentalism. While Noss and Cooperrider (1994) consider scientists to have been the leaders of the conservation movement, Lawton $(1997, \mathrm{p} 4)$ stresses that 'at its heart, conservation is not a scientific activity'. The establishment of conservation reserves is not a scientific process: the critical decisions are political, social and cultural. The questions at the beginning of the conservation process are socio-political questions: what do we want to conserve? Why? In what state? These centre around cultural values, political priorities and historical contexts.

Cronon (1995) collected a challenging set of papers from the results of an extended multidisciplinary seminar. The same broad research project also produced Soulé and Lease (1995), subtitled 'Responses to postmodern deconstruction', and specifically intended as a reply to Cronon (1995). Both these collections are highly significant for their content and their subsequent impact, with a number of conservation scientists supporting Soulé's criticisms, and many hostile responses to the chapters in Cronon's book. Soulé argues that the conservation movement mobilises essentially around the premise that 'living nature is under siege' by humans (1995, p145). This dualistic and oppositional portrayal of nature and human society has been fundamental to Western worldviews. In the last two decades, scholars from a range of fields have challenged this view, analysing the idea of nature as 'socially constructed'. A social constructionist view of 'reality' argues that 'truths' like Soulé's 'living nature', are the cultural stuff out of which broad moral and material systems are made. They are 'maps of meaning' that whether 'right' or 'wrong' are picked up by people, groups and institutions. They are acted upon, reproduced and hardened into seeming 'fact' (Anderson and Gale 1999).

Conceiving of nature in this way means recognising that the way we describe and understand the world is intimately bound up with our own values and assumptions. Perceptions of nature 'out there' are necessarily mediated through human senses and intellects, and the cultures in which people live. This position challenges the nature/culture dualism, and also alludes to arguments that what has been assumed was 'natural' is in fact enormously influenced by anthropogenic forces over long periods. Proctor (1998b), reviewing the Cronon-Soulé debate, and discussing the centrality of wilderness to the argument, identifies an important point: that there is confusion 
between arguments about what wilderness is, in 'reality' (has this particular area been strongly influenced by human action in the past?) and ideas of wilderness (is wilderness an American concept that has little relevance in some other cultures?). Cronon (1995) argues that one of the streams of enquiry that has promoted new thinking of the meaning of nature in the modern world is the 'new ecology' (see for example Worster 1995). This work argues that nature is more accurately characterised as dynamic, unstable and uncertain, than stable and balanced. This paradigm shift is important not only for its ecological significance, but because it reveals both the immense importance of a paradigmatic theory for decision-making, and the influences of Western culture on the development of such paradigms. Callicott and Nelson (1998) summarise and extend these debates. While these published discussions are a decade old, the debate continues, both in academic and in policy terms.

The conservation movement and conservation agencies are grappling with these pressures to change the myths. One broad group is responding by arguing that the myths (theories) hold up, as long as we have more and better of conservation-as-usual. Muir (2005, p8) suggests that 'this distance between the two dreamings [Western and Indigenous 'wilderness dreamings'] will increase as Indigenous communities living in a wilderness area use modern technology more intensively and extensively over time', and argues that this contradicts wilderness principles. Other groups argue for a new paradigm, where nature is pervasive and conservation is a social issue. Hill (2004, p15) analysing the Fifth World Parks Congress in Durban, 2003, reports that wilderness proponents strongly argued their case in response to 'widespread recognition that most near-natural areas are the homelands of Indigenous peoples'.

Within the New South Wales state conservation agency (the Department of Environment and Climate Change), a number of researchers have produced publications implicitly and explicitly questioning the legitimacy of wilderness as a central organising and policy theme in the agency. Harrison (2004) examines 'shared histories' between Aboriginal people and settlers in the pastoral industry in New South Wales, pointing out the surprising fact that over 95\% of the lands now managed as conservation estate (including 'wilderness') have 'at some point been used as pasture for grazing' (pxi). The shared history of pastoralism has largely been erased (or at least ignored) by contemporary conservation management approaches in these same landscapes, which have tended to prioritise a view of conservation landscapes as 'natural' rather than 
cultural. Byrne and Nugent (2004) also explores post-contact Aboriginal heritage, identifying the places in rural and coastal communities where Aboriginal people had and have managed to maintain access to particular types of terrain. Areas of coastal swampland, for example, were marginal to the agricultural economy, and consequently available to Aboriginal people. Much later, when they became perceived as valuable for conservation, new restrictions were applied to Aboriginal use. English (2002) documents a specific region in New South Wales to demonstrate the failure of existing heritage laws to protect sites of significance to Aboriginal people, where those sites are used for accessing wild resources but do not have associated 'heritage items'.

While these and other researchers, from within this conservation agency, have uncovered contradictions inherent in current policy and management, the sections of the agency with authority for managing the conservation estate tend to continue to have views based on the wilderness model. The last published Annual Report for the Department (DEC 2006, p 62) refers to a recent wilderness addition to the conservation estate, and concludes: 'this brings the total area of declared wilderness to almost $1,900,000$ hectares, which represents $29.5 \%$ of the total DEC estate and $2.39 \%$ of the total land area of NSW'.

\section{Homelands}

Aboriginal writers have challenged the relevance of the wilderness concept in Australia, unpacking the ongoing colonial assumptions implicit in declaring land empty of people (Bayet-Charlton 2003, Langton 1996, 1998). Others have explored the significance of land as homeland, and have argued for the necessity of Aboriginal presence in maintaining the integrity of these landscapes. In northern Australia in particular, there is mounting evidence that separating Indigenous people and their home landscapes has negative conservation outcomes (Yibarbuk 1998, Rose et al 2002, Murphy and Bowman 2006).

Langton (1998, p19) quotes the then Aboriginal and Torres Strait Islander Commission's proposal for a definition of wilderness as land 'without its songs and ceremonies', making explicit the history, and the ongoing need for a deep connection between particular peoples and particular places. 
These statements are a clear challenge to the assumed beliefs about the place of wilderness in Australian conservation. Many Aboriginal people want to insist on the rightness of their connections to Country, and the need for Australian landscapes to continue to co-evolve with the people who have lived here for millennia. While there is much literature on these issues focusing on remote Australia, recent unpublished work by a young Indigenous scholar strongly argues for recognition of the continuity of Aboriginal presence and Aboriginal knowledge in places close to white settlement, such as north coast New South Wales (Cavanagh 2007).

Different intentions founded on quite different understandings may result in the same outcomes on the ground. Neither Aboriginal people nor conservation professionals necessarily have to 'give up' their worldviews: they have to understand the other parties' worldviews. What they have to give up is the assumption of the hegemony of their worldview. This understanding establishes the conditions for respect, and ethical negotiation. Positive outcomes for biodiversity conservation on the ground can be produced by Aboriginal social and spiritual understandings and actions, and also result in improved social justice outcomes for Aboriginal people. Positive outcomes for Aboriginal people can be produced by conservation biologists' skills in managing threatened species and species reintroduction programs, supporting the survival of species which are spiritually and economically important to Aboriginal people.

A key challenge here is to do with systems of knowledge and consequent communication:

...Indigenous and western knowledge systems are different pathways of knowledge: they are embedded in different world views, they are transmitted differently, they organise human action and human authority differently (Rose 2001 р 6).

Conservation professionals' assumptions about the hegemony and 'truth' of science may impede them from discussing their plans with the relevant Aboriginal people. Different Aboriginal systems of knowledge which do not assume or accept that all knowledge is open and available may affect communication processes with non-Aboriginal people. 
Being aware of, and understanding, the differences are first steps to working through these challenges and developing appropriate processes for negotiation.

I am not advocating that Westerners, non-Aboriginal people, start to think like Aboriginal people. I suggest that they need to recognise the nature and limits of their own knowledge systems and thinking, and see where Indigenous ones may contribute to solving 'conservation problems' in this country. While Indigenous knowledge systems may themselves function in terms of 'symmetrical complementarity', it is the acceptance of complementary (Indigenous-Western) understandings, rather than the adoption of Indigenous systems that I argue is necessary. The functional complementarity of Indigenous systems is perhaps what has enabled many Aboriginal and other Indigenous people to adopt and adapt many aspects of Western understandings, to apply to the changed environmental and social landscapes where we now all find ourselves.

Acknowledging the limits of one's own epistemology and the strengths of others can provide the basis for transformative learning. Concepts of complementarity can provide the framework for new defining myths of appropriate relationships with land and biota. New relationships between conservation agencies and Aboriginal people can be built using the recognition that better results for both might ensue.

Complementarity functions as a transforming myth, a new vision as foundation for the movement from crisis to alternatives. This vision then sustains the development of new policy and implementation: old beliefs are unlearnt, and new futures strategically framed. New, bridging, institutions are developed, redefining relationships.

Insertion of reciprocal partnerships between conservation interests and Aboriginal communities, based on complementarity, could help respond to the challenges of a rapidly changing landscape. While outcomes are likely to be uncertain, that is not different to the situation now. The attraction is in the idea (with some evidence) that the different worldviews may, in fact, significantly overlap in on-ground management outcomes: different values and intents can result in similar physical scenarios. A physical result that derives directly from spiritual beliefs, for example, need not be quantitatively or qualitatively worse than (or even different to) one deriving from scientific beliefs. 


\section{Spaces for Change}

The concept of the 'recognition space' suggests a spatial metaphor for relationships between Aboriginal people and the rest of Australian society (first used by Pearson 1997, then Mantziaris and Martin 2000). The recognition space is both a theoretical condition (a framework for negotiation that is inclusive and open to learning on both sides), and a geographic place. This section examines some possible recognition spaces in terms of geography and tenure.

The recognition space as a geographic location is a new meeting place where at least two things can happen. One is that groups of people (Aboriginal and conservation agency staff) who may otherwise not meet at all have an incentive to discuss shared interests in land. The other is that the relationships between the groups is different to that historically applying, with relations of power being either approximately equal, or weighted in favour of the Aboriginal groups. These spaces for change reflect broader processes as well: changing social values ascribed to the 'left over lands' of the twenty first century, and the layers of contestation over existing titles and tenures.

Analysing 'landscapes of segregation', Byrne (2001) highlights Aboriginal persistence in the 'gaps and corners' of otherwise colonised places, and the practice of fence-jumping (trespassing). While Byrne is writing from a cultural heritage perspective, the implications of colonial cadastral incompleteness are also expressed in contemporary conservation interests: the 'left over lands' are increasingly the 'crown jewels' of undeveloped nature, to be made into conservation reserves, and regulatory approaches in conservation jump fences to protect 'biodiversity' on 'private' lands.

There are other meeting places as well, where the recognition spaces are not ones where Aboriginal people actually own the ground in Western terms. In conservation agencies, management of 'cultural heritage' has been an important site for meeting, but there are important problems around definitions of culture and authenticity, and it is only recently that these are being strongly challenged within agencies (see, as previously discussed, Harrison 2004, Byrne and Nugent 2004, English 2002).

Another suite of recognition spaces are those where personal, local relationships develop into agreements about access to conservation land for cultural and social uses. 
These are important spaces because they acknowledge the significance of the personal and the local, and because they are usually developed far from 'head office' cultures they can escape some other constraints. Their crucial limitation is the (usual) lack of a legal or rights-based framework: they are dependent on the continuity of the personal relationship, and in situations of high staff mobility and short bureaucratic memory, this makes them very vulnerable. Acknowledging these strengths and limitations, they may have an important role as the precursor or introduction to a more formal, rights-based arrangement.

Where land rights or native title have delivered exclusive tenure (most notably in the Northern Territory, but in small and sometimes significant parcels in the eastern states as well), the authority supplied by property regimes has passed to Aboriginal people. Many of these places have high conservation value. Consequently, state conservation agencies must meet with these Aboriginal owners to negotiate, if the state wishes to participate in the management of the conservation values. If however, the only real meeting places are created after Aboriginal people have regained rights to land, the potential is limited: this perpetuates the situation where Aboriginal people force others to the negotiating table by law or judicial decision. It is processes of structural and attitudinal change which are necessary to create the opportunity for new meeting places - recognition spaces - across the landscape.

\section{Redefining Relationships}

Processes of institutional change are where complementarity and the recognition space become operationalised. This section examines the processes for institutional change that might be appropriate to respond to the policy inadequacy that currently prevails. It follows from the observation that improving the performance of natural resource systems requires an emphasis on institutions and property rights' (Berkes and Folke 1998 p 2). This approach has been investigated extensively in relation to agricultural practices and landcare in Australia, but not in biodiversity conservation, and relatively recently for Aboriginal issues (see Mantziaris and Martin 2000). The corresponding social change lies in breaking down the compartmentalisation of issues: 'Aboriginal people bring a large bundle of issues into their conversations about environments' (Rose 2001 p 6). Institutions are fundamentally cultural entities - examination of them within 
their cultural frameworks can help reveal the places for negotiating change: the recognition spaces.

On the conservation agency side, the problem is founded in (i) its assumptions about government control of conservation management; (ii) 'scientific' criteria for reserve development; and (iii) the defining agency construction of nature. Accordingly, Aboriginal claims are perceived as unacceptable, because the agency would have to relinquish greater or lesser degrees of control over conservation estate or issues; and the claims might compromise (or ignore) accepted criteria for the reserve system. Agency landscapes are full of biodiversity and natural values, to be studied, protected, appreciated, and used for recreation. From the point of view of Aboriginal people, the problem is founded in assumptions about the rights of First Nations, cultural continuity, social equity and economic independence. Aboriginal landscapes are home and hearth, places lived in and worked in, full of spirit, history, and social values. Fundamentally, the Aboriginal constructions of nature challenge the agency ones.

\section{Tenure, rights and management}

Cross-cultural collaborative approaches, like others, require at least two parallel processes: 'product-oriented' dimensions, and 'process-oriented' dimensions. There is obvious overlap between these, as 'products' (for example, plans of management) may well specify 'processes' (for example, new relationships and responsibilities), and vice versa. There will be various challenges here: state government staff are generally unused to adaptive, interactive negotiation: there may well be perceived 'turf' problems; and there are complex inter-cultural issues.

While legislation is by no means the only institutional structure affecting processes and outcomes, it is certainly a dominant one. It can explicitly prohibit, or specify, particular activities or relationships. Often however, legislation is vague or contradictory. These various characteristics can be positive or negative for negotiating new relationships. Where legislation is 'silent' on a particular issue, then potentially there is nothing to stop activities in that area proceeding. Where legislation is contradictory, it may be possible to use one part to allow something apparently prevented by another part. Where legislation specifically prohibits a desired activity or relationship, then a process 
of legislative review and reform will be necessary. I am not a lawyer, so I am not going to analyse the detail of 'black letter' legislative amendment which is potentially necessary, but focus instead on policy and institutional arrangements.

\section{Mechanisms}

The diversity of government conservation agencies under the Federal system, combined with increased involvement by environment NGOs in conservation reserve declaration and management means that a diversity of tenures will continue to be used for protected areas in Australia. In discussing processes for change, I review three broad areas of tenure attempting to embrace Aboriginal and conservation interests, which effectively already exist at various levels of explicitness. As I am focusing on tenure and rights including property rights, I do not examine in detail various other processes such as formal or informal arrangements for Aboriginal people to access national parks which stop short of recognising explicit rights. The three areas are: (i) joint management arrangements, (ii) 'Indigenous Protected Areas' and (iii) the Indigenous estate and its contribution to conservation. These three are clear 'tenure' manifestations of the various recognition spaces discussed earlier. While the three are all different versions of a single theme (Aboriginal owned land managed for conservation), the second and third demonstrate clearer Aboriginal autonomy, 'self-declaring' the conservation status of their land., so the three mechanisms can be seen as a progression in terms of increasing Aboriginal autonomy and rights.

\section{(i) Joint Management Arrangements}

Woenne-Green et al (1994) comprehensively analysed Aboriginal participation in national parks in all Australian jurisdictions, with a focus essentially on various different forms of 'joint management'. Smyth (2001) again briefly reviews all jurisdictions. All of the existing joint management arrangements are based on some form of claim under a statutory land rights or native title process, or by specific Acts of Parliament. To date, formal joint-management regimes exist for parks in the Northern Territory, New South Wales, South Australia, Jervis Bay Territory and the Australian Capital Territory (Bauman and Smyth 2007).

Examples from two states show the range of possibilities. In NSW, there is a long process of negotiation to achieve hand back of land and joint management under lease- 
back arrangements, and so far five national parks have negotiated lease-back arrangements, two have non-statutory co-management agreements, and one is jointly managed under a native title agreement (out of 677 protected areas in NSW). While Baird and Lenehan (2001), reviewing the results of the lease-back legislation at that date, concluded that the government was not committed to progressing further such arrangements, joint management agreements have continued to develop. Feary (2001) and Lowe and Davies (2001) discuss various impediments to achieving joint management under a lease-back arrangement in the New South Wales part of the Jervis Bay region. The Jervis Bay Territory, geographically within New South Wales but administratively separate, contains Booderee National Park, reviewed by Bauman and Smyth (2007). The Booderee Plan of Management refers to a goal of achieving 'solemanagement' at Booderee, which is unique in published joint management plans, but there is no consensus on what this might be or how it might be achieved (Bauman and Smyth 2007).

In the Northern Territory, Garig Gunak Barlu National Park (reviewed after ten years of operation by Foster 1997), and Nitmiluk National Park (reviewed by Bauman and Smyth 2007), demonstrate two models for collaborative management. The two Commonwealth managed joint managed parks (Kakadu and Uluru-Kata Tjuta) are often claimed as world-leading innovations. A native title driven process commencing in 2003 may see 49 out of 90 Northern Territory national parks returned to Aboriginal owners and jointly managed (Northern Territory Parks and Reserves [Framework for the Future] Act 2003). All of these models, which vary considerably and span a period from 1981 to the present, have successes and limitations, and continue to evolve within the limits of their establishing legislation.

Across this spectrum of possibilities, all forms of joint management have limitations in terms of Aboriginal control, as well as perceived limitations from the conservation agency side. Smyth (2001 p 76) summarises:

A key element in these arrangements is that the transfer of ownership back to Aboriginal people is conditional on their support (through leases or other legal mechanisms) for the continuation of the national park. It is therefore an arrangement of convenience or coercion, rather than a partnership freely entered into. 
For many Aboriginal people, the way joint management operates appears to be about teaching Aboriginal people to be 'whitefella' park managers, rather than negotiating an entirely new form of conservation management. After more than twenty years of joint management, in 2006 Uluru-Kata Tjuta National Park appointed its first Aboriginal park manager. In New South Wales, many Aboriginal people perceive the state conservation agency as perpetuating non-Indigenous values in the management of Indigenous country and culture (Adams, Cavanagh and Waddell 2007).

While joint management as it exists across Australia today could more accurately be described as a contested negotiation process rather than a collaborative one, it is likely that joint management scenarios will continue to be the preferred 'solution' to many issues. Further development of the concept, and increasing experience by conservation agencies and Aboriginal people in the practice, may improve functioning and outcomes.

\section{(ii) Indigenous Protected Areas}

The analysis of Australia's biogeographic regions and their relative representation in protected areas (Thackway and Cresswell 1995), revealed that to achieve a 'comprehensive, adequate and representative' National Reserve System it would be necessary to include some land already owned by Aboriginal people. The concept of Indigenous Protected Areas (IPAs) was developed by the Commonwealth to achieve this (Smyth and Sutherland 1996).

The primary objectives of the Indigenous Protected Areas Program of the Department of Environment, Water, Heritage and the Arts are to establish partnerships between government and Indigenous land managers to support the development of a 'comprehensive, adequate and representative' national system of protected areas. It is intended to achieve this by assisting Indigenous people to establish and manage protected areas on lands to which they hold title, and assisting Indigenous groups and Commonwealth, State and Territory agencies to develop partnerships and agreements for the cooperative management of existing protected areas. The program also intends to promote and integrate Indigenous ecological and cultural knowledge into contemporary protected area management practices. 
Recent statistics indicate that over 14 million hectares have been declared as Indigenous Protected Areas in twenty two sites around Australia (Gilligan 2006). Most of these are in central and northern Australia, with three IPAs covering nearly twelve million hectares between them. Commonwealth funding for IPAs is now around \$3million/per year, totalling around \$18 million since 1996.

The Indigenous Protected Areas concept may be very positive in the long term. It may support Aboriginal access to land management resources, and its articulation to international policy processes may help influence national and state ones. In particular, its specific association with the World Conservation Union (IUCN) categories links it to the IUCN policy on Indigenous and Traditional Peoples and Protected Areas (Beltrán 2000), which establishes a progressive framework for these relationships. Langton, Rhea and Palmer (2005) argue that the owners of IPAs operate from a position of strength: they already own the land, so are not dependent on a conservation agency making a place for their involvement. Instead, government is approaching the landholders requesting their involvement. An independent evaluation in 2006 concluded that the program was 'highly successful' (Gilligan 2006, p 58). Smyth (2007) has suggested further possibilities to what is already a very successful innovation.

\section{(iii) Indigenous (Conservation) Estate}

The research by Thackway and Cresswell (1995) also revealed the extent of Indigenousheld land which contributes 'informally' to conservation. That is, the sometimes very large areas which are managed in such a way that, either deliberately or by 'default', their 'natural' values are conserved. Pollack (2001) argues that as much as $16-18 \%$ of Australia was 'held' by Indigenous people in 2000, with that percentage expected to increase; contrasted to the estimated $7.84 \%$ of Australia in the protected area estate in that year (Hardy 2001). SCRGSP (2007) confirms that in 2006 a minimum of $16 \%$ of Australia was Indigenous held land, and more than 98\% of that is in areas classified as 'very remote’.

The situation in the Northern Territory is significantly different to that in most of the rest of Australia. Nearly 50\% of the land area of the Northern Territory is Aboriginal land, and more than $70 \%$ of the Territory's Aboriginal population live on that land (Altman and Whitehead 2003). Various assessments have concluded that the 
biodiversity of much of that land, particularly in the northern savannas, has very high biodiversity value which is maintained by Aboriginal customary management practices (see Yibarbuk et al 2001, Murphy and Bowman 2006). This land makes a very significant contribution to Australia's conservation goals, but one that is largely not acknowledged. In addition, as mentioned above, around half of Northern Territory national parks will be returned to Aboriginal owners and jointly managed. In the Northern Territory, Aboriginal people are key players in conservation initiatives and outcomes.

Generally, the contribution of Aboriginal land to biodiversity conservation outcomes will be variable. It is very unevenly distributed, and has been subject to widely varying levels of environmental impact. Many areas in the north of Australia (for example Arnhem Land and parts of Cape York) may have been subject to relatively low levels of non-Aboriginal human induced change, while other areas in the rangelands and southern Australia may have been far more influenced by grazing and other activities (see for example Landsberg et al 1997).

I will briefly examine two aspects of this 'Indigenous estate' here: the implications of this estate functioning largely independently of government policy and mechanisms; and the treatment by government of these lands relative to its treatment of nonIndigenous freehold and leasehold lands. I then examine the opportunities for government and Aboriginal people in seeking policy connections.

In the first aspect, large areas of the Indigenous estate currently operate effectively independently of any government conservation policy or mechanisms. This is a reasonably explicit reflection of 'purified' notions of 'real nature', and the imperatives for command and control in government conservation agencies. Governments are not in a position to exert much command and control on Indigenous-held land, and have historically baulked at effectively responding to conservation issues in landscapes occupied by resident people. In such cases, while the land may indeed 'contribute' to national and state biodiversity conservation objectives, it does so at little cost to government. Ironically though, it is unlikely to be acknowledged as contributing, because there are no formal arrangements, including monitoring ones. 
Estimates by a group of ecological and environmental scientists from the Northern Territory (Woinarski, Mackey, Nix and Traill 2007, p81) suggest that that the costs to government for land management at Kakadu National Park are around \$725/square kilometre. Immediately east of the Kakadu boundary, the costs to government of land management on the Aboriginal land section of the Arnhem Land plateau, are around $\$ 0.83 /$ square kilometre. There is no suggestion that the biodiversity outcomes are different across that border, and the border straddles a key biodiversity 'hotspot', the Arnhem Land Plateau.

The extent of Indigenous-held lands is of an order of magnitude comparable to the freehold and leasehold lands held by the non-Indigenous population. These lands have been, and are, the subject of significant attention by resource agencies in government. Numerous programs exist to support landholders in land management objectives which meet national policy directions, such as Landcare. These programs typically fail to respond proportionately to Indigenous concerns or Indigenous lands (Altman and Whitehead 2003). One reason for this is that much policy effort is focused on 'productive' landscapes: that is, on attempts to achieve 'ecologically sustainable' production on agricultural and pastoral lands subject to various forms of land degradation. In these lands, significant resources are being provided, essentially untied to command and control structures, to landholders to assist management of their lands. Much Aboriginal land is seen as being outside the (Western) systems of production. The failure to provide equivalent levels and types of resourcing to Aboriginal landholders has been repeatedly raised, most recently in relation to new proposals for 'stewardship' funding directed to farmers for environmental management of the $60 \%$ of the land mass they control. A coalition of environment groups is lobbying for this to be extended to Indigenous landholders and others (Wilderness Society et al 2006).

The second aspect suggests a new policy connection between Aboriginal lands and conservation objectives. In a Queensland review of policy for Indigenous interests in protected areas, Johnston and Yarrow (1999), proposed a new category: 'Indigenous national park'. This proposed what would effectively be 'contract-managed' national parks, where the managing agency would be an Indigenous organisation operating under an agreement with the Minister for Environment, and resourced by the state. The significance of this new category, at one level, is its recognition of the multiplicity of protected area regimes operating in Australia. These regimes include entirely private, 
non-government regimes such as the Bush Heritage Fund and the Australian Wildlife Conservancy. Governments provide various levels of recognition to these regimes, and their recent growth would indicate they will become more significant over time (Figgis 2004).

While the bulk of the Indigenous estate is in northern and central Australia, there are regionally-significant Indigenous land holdings in southern states as well. In western Sydney, an area near Maroota was successfully claimed by a local Aboriginal Land Council under the NSW Aboriginal Land Rights Act 1983. This land, now owned by the land council, had previously been proposed as a national park, contains significant rare species, and is large enough at 4,500 hectares to be effectively managed for its Indigenous and conservation values (Adams 2004).

There has been a growing focus on the concept of Aboriginal rangers on Aboriginalowned land, and there are numerous 'caring for country' units established across northern Australia. Recent research suggests that these people, and these lands make a very significant and undervalued contribution to conservation management (Altman, Buchanan and Larsen 2007).

The category of 'Indigenous national park' could be an entirely appropriate response to situations of both policy inadequacy and resourcing difficulties associated with 'remoteness'. In numerous 'remote' locations there is a permanent resident Aboriginal population actively engaged in caring for country contrasted with a transient, underfunded, and unhappy state ranger presence. In some urban and regional areas, while there are not resource difficulties associated with remoteness, the combination of some Aboriginal owned land and a large Aboriginal population could also be effectively mobilised by a system of 'Indigenous national parks' which recognised contemporary cultural connections and responded to employment and social justice issues. In both cases, a detailed agreement with the relevant state minister would provide the appropriate articulation to state conservation objectives. Neither of these scenarios is outlandish: there are geographic precedents in the private regimes operating in similar circumstances. The challenge for conservation agencies is to develop regional and state conservation strategies which embrace conservation agency estate, NGO and private conservation estate, and Aboriginal estate. 


\section{Redefining Relationships}

The preceding section examines some possibilities in the 'product' dimension of collaborative policy change. This section examines elements of the 'process' dimension, including the necessity for both structural and attitudinal change. Often attitudinal change (change in values or even just in attitudes to values) is far more challenging than structural and product-oriented change, although these latter are critical to the ongoing nature of the policy resolution.

In conservation agencies, the primary challenges are in stimulating attitudinal change that does not flip into another negative scenario, the most obvious being an 'elevation' of Aboriginal values to 'noble savage' status. Instead of creative and critical thinking around the uncertain issues of how contemporary conservation can be negotiated between Aboriginal people and agencies, there is a shift to a different 'certainty': that 'they' have it right and 'we' have it wrong. Some Aboriginal people, attempting to contest western hegemonies, have used these arguments themselves, adopting a notion of unchanged continuity from a past golden age which can be unproblematically brought into the present.

A related example is in the common assumption that the way to integrate Aboriginal interests with conservation objectives is through incorporating, or otherwise acknowledging, 'traditional ecological knowledge'.

The limits of the 'traditional ecological knowledge' approach can be contrasted with the challenges of engaging holistically with Indigenous epistemologies. The work of both Bruce Rose (1995) and Deborah Rose (1992) brings out some of these elements, and publications by Aboriginal intellectuals examine these issues in detail (for example Yunupingu 1994, Langton 1998). The key attitudinal challenge then, is accepting that Aboriginal knowledge and values (with traditional ecological knowledge as an example rather than the corpus) are embedded in holistic and comprehensive epistemological structures, just as are Western knowledge and values. And, just as in Western forms, these are dynamic, evolutionary and exploratory, engaging with a changing world: the same world, but understood differently. 
While innovative policy change may to some extent convince the top of the Government hierarchy, the challenge is to embed the changed understandings into the other levels of the organisations. Leadership faces the challenge of codifying the alternatives into the new round of policy - to move through the phase of reconfiguring knowledge, underwritten by new organising myths, into the phase where bureaucrats once again implement (new) policy. In many state conservation agencies there is not, however, evidence that a new 'organising myth' has been clearly articulated: it might be too soon, or it may be that no-one has managed to define one coherently enough. There is, however, certainly evidence that people are aware of the need for one. The titles of English and Brown (2001) It's a part of us, and the Australian Heritage Commission's pamphlet (1998) Wilderness, we call it home, are indications of attempts from the Aboriginal side of the recognition space to express a new myth. In New South Wales, one senior manager is using the expression reconciliation with the land in a similar attempt. Each of these statements is recognition of the importance of the role of the defining myth. The dominance of the 'Uluru model' both within Australia and internationally is a reflection of this (and also an example of newly configured myths).

\section{Conclusions}

Solutions to the pathology of consistent policy inadequacy in this area will need to be applied at multiple scales. While political will is obviously important, political cycles are short and volatile. Institutional change at organisational and policy levels exerts pressure both upwards, influencing ministers and government, and downwards, influencing practice. Conservation agencies can and do influence politics and politicians. They also clearly influence relationships with other parties, and on-ground outcomes. They have a high level of control over management of their own 'estate', significant control over acquisition of new land, and some control over plants and animals ('biodiversity') on all land. They have (Western) legal responsibility for protecting and managing Aboriginal cultural heritage (albeit narrowly defined).

Aboriginal people have an interest in all national park lands, partly for the same reasons that all Australians do, and partly for quite different reasons: it was once all their land, and they have particular historic, social, economic, ecological and religious connections to it. 
The success and possible continued innovation of Indigenous Protected Areas is an indicator of positive policy evolution. Recognition of the significance of Aboriginal ranger programs, and adequate funding to resource them, seems likely to increase under new national government arrangements. It is unclear how joint management, in all its forms, will evolve: there is much evidence that in very many situations is has been contested and conflictual, and this may well persist. In a situation where the dominant party is a mainstream government agency, significant change which acknowledges and prioritises an alternative set of worldviews will be a challenging prospect.

The advantage of the level of policy inadequacy in this area is that it sets conditions for learning: if policies appear to be working, there is no incentive to learn. However, if successful assessment of the situation is followed merely by cumbersome process and a formalisation of relationships, good results are unlikely. These issues are complex, highly related to other issues, span long time frames and involve contesting, or at least, negotiating, values: policy macro-problems.

I am not suggesting that it is possible to achieve 'certainty' or 'closure' on these issues: instead, redefined relationships offer the possibility of new connections between people as the basis for jointly working through continuing and inevitable uncertainties.

\section{Bibliography}

Adams, M., Cavanagh, V., and Waddell, L. (2007) Audit of partnerships between Aboriginal people and the Parks \& Wildlife Group of the NSW Department of Environment and Climate Change, unpublished confidential report, Woolyungah Indigenous Centre, University of Wollongong.

Adams, M. (2004) "Negotiating nature: collaboration and conflict between Aboriginal and conservation interests in New South Wales, Australia”, Australian Journal of Environmental Education 20.1, pp 3-11.

Altman, J., Buchanan, G., and Larsen,L. (2007) The environmental significance of the Indigenous estate: natural resource management as economic development in remote Australia, CEAPR Discussion Paper No 286/2007, Centre for Aboriginal Economic Development, ANU, Canberra.

Altman, J and Whitehead, B. (2003) Caring for country and sustainable Indigenous development: opportunities, constraints and innovation, Centre for Aboriginal Economic Policy Development, ANU, Canberra.

Anderson, K., and F. Gale (1999) “Introduction”, In Cultural Geographies, edited by K. Anderson and F. Gale, Melbourne: Longman, 
Australian Heritage Commission (1998) Wilderness, We Call it Home (pamphlet), Australian Heritage Commission, Canberra.

Baird, W., and R. Lenehan (2001) An update on the process in NSW leading to joint management of Aboriginal owned land and the register of Aboriginal owners, Paper read at Native Title Representative Bodies Legal Conference, 28-30 August 2001, at Townsville.

Bauman, T., and Smyth, D. (2007) Indigenous Partnerships in Protected Area Management in Australia: Three Case Studies, AIATSIS, Canberra.

Bayet-Charlton, F. (2003) "Overturning the doctrine: Indigenous peoples and wilderness - being Aboriginal in the environment movement”, in Blacklines: Contemporary Critical Writing by Indigenous Australians, edited by $\mathrm{M}$. Grossman, Melbourne University Press, Carlton, Victoria pp 171-80.

Beltrán, J. (2000) ed. Indigenous and Traditional Peoples and Protected Areas: Principles, Guidelines and Case Studies, IUCN, Gland Switzerland and Cambridge, UK and WWF International, Gland, Switzerland.

Berkes, F. and C. Folke (1998) "Linking social and ecological systems for resilience and Sustainability”, In Linking Social and Ecological Systems: management practices and social mechanisms for building resilience, edited by Fikret Berkes, Carl Folke, Johan Colding, Cambridge: Cambridge University Press, pp. 1-26.

Bowman, D., Price, O., Whitehead, P. J., and Walsh, A. (2001) "The 'wilderness effect' and the decline of Callitris intratropica on the Arnhem Land Plateau, northern Australia”, Australian Journal of Botany 49(5) 665 - 672.

Byrne, D., (2001) Landscapes of segregation, Paper read at The Power of Knowledge, the Resonance of Tradition - Indigenous Studies, September 2001, at Australian National University

Byrne, D., and Nugent, M. (2004) Mapping Attachment: a spatial approach to Aboriginal post-contact heritage, Department of Environment and Heritage (NSW), Sydney.

Cavanagh, V. (2007) The NSW Threatened Species Conservation Act in the Bundjalung Aboriginal Nation, unpublished BSc Honours thesis, University of Wollongong.

Callicott, J.B. and Nelson, M. (1998) The Great New Wilderness Debate, University of Georgia Press, Athens, Georgia.

Cronon, W. (ed.) (1995) Uncommon Ground: Toward Reinventing Nature, New York: W.W.Norton.

DEC (2006) NSW Department of Environment and Conservation Annual Report 20052006, NSW Department of Environment and Conservation, Sydney.

English, A. (2002) The Sea and the Rocks Give Us a Feed. Mapping and Managing Gumbaingirr Wild Resource Use Places, North Coast NSW, Sydney: National Parks and Wildlife Service.

English, A., and C. Brown (2000) It's A Part of Us: Aboriginal People's Perspectives on the Cultural Values of Biodiversity in New South Wales, Sydney: National Parks and Wildlife Service.

Feary, S. (2001) "Moving towards joint management in New South Wales: a Jervis Bay case study”, in Working On Country: Contemporary Indigenous Management of 
Australia's Lands and Coastal Regions, edited by R. Baker, J. Davies and E. Young, South Melbourne: Oxford University Press, pp 276-292.

Figgis, P. (1999) Australia's National Parks and Protected Areas: Future Directions, Sydney: Australian Committee for IUCN.

Figgis, P. (2004) Conservation on private lands: the Australian experience, IUCN, Gland, Switzerland and Cambridge, UK.

Foster, D. (1997) Gurig National Park: the first ten years of joint management, Australian Institute of Aboriginal and Torres Strait Islander Studies Report Series, Canberra.

Gilligan, B. (2006) The Indigenous Protected Areas Programme 2006 Evaluation, Department of the Environment and Heritage, Canberra.

Grove, R.H. (1992) “Origins of Western Environmentalism”, Scientific American July: pp 22-27.

Grove, R. H. (1995) Green Imperialism, Cambridge: Cambridge University Press.

Hardy, A. M. (ed.) (2001) Terrestrial Protected Areas in Australia: 2000 summary statistics from the Collaborative Protected Areas Database (CAPAD), Canberra: Environment Australia.

Harrison, R. (2004) Shared Landscapes: Archaeologies of attachment and the pastoral industry in New South Wales, University of New South Wales Press, Sydney.

Hill, R. (2004) Global trends in protected areas: a report on the Fifth World Parks Congress, Research Centre for Tropical Rainforest Ecology and Management. Rainforest CRC, Cairns. (60 pp). Unpublished report. December 2004.

Johnston, R., and D. Yarrow (1999) A proposal for an Indigenous Conservation Estate, Brisbane: Queensland Indigenous Working Group.

Landsberg, J., C. James, S. Morton, T. Hobbs, J. Stoll, A. Drew, and H. Tongway (1997) The effects of artificial sources of water on rangeland biodiversity, Canberra: Environment Australia.

Langton, M. (1996) “Art, wilderness and terra nullius”, In Ecopolitix IX: Perspectives on Indigenous Peoples Management of Environment Resources, Darwin: Northern Land Council, pp 11-24.

Langton, M. (1998) Burning Questions: Emerging Environmental Issues for Indigenous peoples in Northern Australia, CINCRM, Darwin.

Langton, M., Rhea, Z.M., and Palmer, L. (2005) “Community-oriented protected areas for Indigenous peoples and local communities”, Journal of Political Ecology, 12, pp 23-50.

Lawton, J. (1997) “The science and non-science of conservation biology”, Oikos 79 (1): pp 3-5.

Lowe, D., and J. Davies (2001) "Bundarwa, Berri-werri, and the bay: traditional rights and bureaucratic boundaries”, in Working On Country: Contemporary Indigenous Management of Australia's Lands and Coastal Regions, edited by R. Baker, J. Davies and E. Young, South Melbourne: Oxford University Press, pp 257-275.

Mantziaris, C., and D. Martin (2000) Native Title Corporations: a Legal and Anthropological Analysis, Leichhardt, NSW: Federation Press. 
Muir, K (2005) Action towards wilderness protection in Australia, Colong Foundation for Wilderness, $<$ http://www.colongwilderness.org.au/CelebratingWilderness/CW_TheBook/KM uir.pdf>

Murphy, B., and Bowman, D. (2006) “The interdependence of fire, grass, kangaroos and Australian Aborigines: a case study from central Arnhem Land, northern Australia”, Journal of Biogeography, 34, pp237-250.

Nash, R. (2003) Wilderness and the American Mind, New Haven: Yale University Press.

Noss, R., and A. Cooperrider (1994) Saving Nature's Legacy, Washington: Island Press.

Pearson, N. (1997) "The concept of native title at common law”, In Our Land is Our Life, edited by G. Yunupingu, Brisbane: University of Queensland Press, pp 150162.

Pollack, D. P. (2001) Indigenous land in Australia: a quantitative assessment of outcomes from legislation and programs, CAEPR Discussion Paper No.222, Canberra: Australian National University.

Rose, Bruce (1995) Land management issues: attitudes and perceptions amongst Aboriginal people of central Australia, Alice Springs: Central Land Council.

Rose, D. B. (2001) Connecting with ecological futures, Position paper prepared for the National Humanities and Social Sciences Summit 26-27 July 2001.

Rose, D.B., D’Amico, S., Daiyi, N., Deveraux, K., Daiyi, M., Ford, L., and Bright, A., (2002) Country of the Heart: An Indigenous Australian Homeland, Aboriginal Studies Press, Canberra.

Salmond, A. (1997) Between Worlds, Honolulu: University of Hawai'i Press.

SCRGSP (Steering Committee for the Review of Government Service Provision) (2007) Overcoming Indigenous Disadvantage: Key Indicators 2007, Productivity Commission, Canberra.

Smyth, D. (2007) "Future opportunities for protected areas", paper presented to the AIATSIS Conference, Forty Years On: Political transformation and sustainability since the Referendum and into the future', Canberra, November 2007.

Smyth, D. (2001) Joint management of national parks, In Working On Country: Contemporary Indigenous Management of Australia's Lands and Coastal Regions, edited by R. Baker, J. Davies and E. Young, South Melbourne: Oxford University Press, pp 75-91.

Smyth, D., and J. Sutherland (1996) Indigenous Protected Areas: conservation partnerships with Indigenous landholders, Canberra: Environment Australia.

Soulé, M., and G. Lease (eds.) (1995) Reinventing Nature? Responses to Postmodern Deconstruction, Washington: Island Press.

Stevens, S. (1997) “The legacy of Yellowstone”, in Conservation Through Cultural Survival, edited by S. Stevens, Island Press, Washington, pp13-32.

Thackway, R., and I. Cresswell (1995) An Interim Biogeographic Regionalisation for Australia, Canberra: Australian Nature Conservation Agency. 
The Wilderness Society and Australian Conservation Foundation (2006) New stewardship scheme needed to recognise and reward Indigenous land managers, Media Release, 30 April 2006,

<http://www.wilderness.org.au/campaigns/wildcountry/Indigenous/stewardship/>

Woenne-Green, S., R. Johnston, R. Sultan, and A. Wallis (1994) Competing Interests: Aboriginal Participation in National Parks and Conservation Reserves in Australia, Melbourne: Australian Conservation Foundation.

Woinarski, J., Mackey, B., Nix, H., and Traill, B. (2007) The Nature of Northern Australia: Natural Values, Ecological Processes and Future Prospects, ANU ePress, Australian National University, Canberra.

Worster, D. (1995) "Nature and the disorder of history", In Reinventing Nature ? Responses to Postmodern Deconstruction, edited by M. Soule and G. Lease, Washington: Island Press.

Yibarbuk, D. (1998) “Introductory Essay”, in Burning Questions: Emerging Environmental Issues for Indigenous peoples in Northern Australia, M. Langton, CINCRM, Darwin, pp1-6.

Yibarbuk, D. , Whitehead, P. J. , Russell-Smith, J. , Jackson, D. , Godjuwa, C. , Fisher, A. , Cooke, P. , Choquenot, D. \& Bowman, D. M. J. S. (2001) "Fire ecology and Aboriginal land management in central Arnhem Land, northern Australia: a tradition of ecosystem management”. Journal of Biogeography 28 (3), 325-343.

Yunupingu, M. (1994) Yothu Yindi: Finding Balance, Race \& Class 35 (4) pp 113-120. 